\title{
Study of A High-rise Building Alarm and Linkage System
}

\author{
Xianjie Feng \\ Department of architectural engineering, dongguan university of technology, china \\ email: fengxianjie@126.com
}

Keywords: High-rise buildings. Emergency lighting design. Pressure switch. Fire linkage control system. Lighting load layout.

\begin{abstract}
In this paper, the electrical parts of a high-rise shopping and office buildings are studied. Firstly, according to the division of the load level, the load calculation is carried out with the method of unit capacity, so as to determine the capacity and the current of the load. In accordance with the protection radius of auxiliary line method, through the calculation to determine the required number of detector, to ensure that no dead zone, fire alarm system is studied. In addition, this paper also studies the linkage control system which is composed of the fire pump, the spray pump, the positive pressure air blower, the exhaust fan, the elevator control and so on.
\end{abstract}

\section{Introduction}

With the continuous development of intelligent building, the building electrical equipment, building power supply system, building lighting system [1], building fire automatic alarm system, building lightning protection grounding system are also in constant development.

Level 1 load of power supply should be made up of two power supply, when a power failure, another power supply should not be damaged at the same time, but in actual design to meet the power supply of a power supply, two high voltage power supply can be used. Level 2 load of power supply requirements should be composed of two lines of power supply back. Level 3 load no special requirements for power supply.

In this paper, a shopping mall and office buildings of the electrical system design. The project building is $\mathbf{5 2 . 5}$ meters high, a total of 15 layers. Among them, the underground as a garage, the first layer as a shopping mall o, the second to the 13th floor for office use, the top layer for the elevator. The building belongs to the kind of high-rise buildings, fire control room, fire pump, fire elevator, smoke and smoke exhaust fan, emergency lighting and so on are all in accordance with the load, the use of dual power supply. Other power equipment lighting electricity for Level 3 load.

\section{Lighting Load Calculation}

Lighting load calculation is generally adopted the method of unit area power [2].

AL0-1 load of the distribution box, the underground layer $\mathrm{W}=30 \mathrm{w} / \mathrm{m} 2$, the power supply area of $\mathrm{S}=339.3$, then total active power $=\mathrm{WS}=1 * 30 * 339.9=10179 \mathrm{w}$.

Considering the actual capacity of distribution box is 3 times more, so the $\mathrm{P}=12 \mathrm{kw}$, a larger allowance.

The calculation of current: $\quad I_{j}=\frac{k_{x} P_{e}}{380 \sqrt{3} \cos \phi}$

$$
=\frac{12 * 10^{3}}{380 \sqrt{3} * 0.8}=23 \mathrm{~A}
$$

The set values for the circuit breaker selected $32 \mathrm{~A}$, conductor is selected to match the circuit breaker, optional YJV5 * 10, its carrying capacity is more than $32 \mathrm{~A}$. 


\section{Emergency Lighting Design}

Emergency lighting can be divided into three categories according to the use: evacuation lighting, safety lighting, standby lighting. Pay attention to the following respectively:

Evacuation emergency lighting: the illumination on the ground of the evacuation passage [3] should be reached 1LX, and the minimum shall not be less than $0.2 \mathrm{~lx}$;

Security emergency lighting: lighting provided by the intensity of illumination on the surface of the work should not be less than $5 \%$ of normal lighting system to provide illumination, and should be in normal lighting power supply disappears within $0.5 \mathrm{~s}$ to provide safety lighting power supply;

Standby emergency lighting: mainly from two levels of power, the power grid power supply and backup power generator (or battery), intensity of illumination is usually $10 \%$ of the normal illumination.

The building adopts the emergency lighting combined with normal lighting. In addition, corridor, toilet, the stairs and so on according to the level of load power supply, and continuous power supply time is not less than 20min. Aisle evacuation marker light spacing within $20 \mathrm{~m}$, installation height meet the related specifications and other requirements. Lighting plan as shown in Fig. 1:

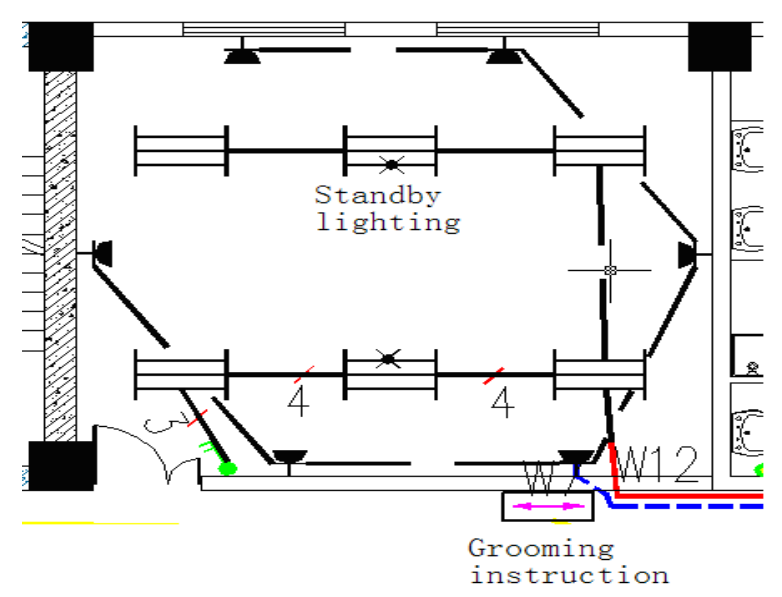

Fig.1. Emergency lighting layout

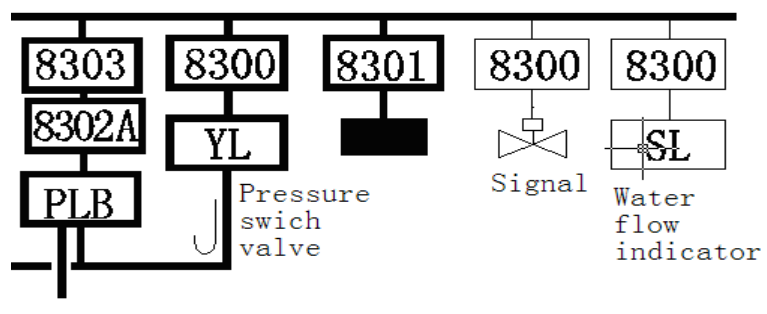

Fig.2. Hydraulic alarm system

\section{Set the Pressure Switch Valve, Water Flow Indicator, Signal}

The pressure switch is used to detect the water pressure in the pipe, which is installed on the pipeline of the hydraulic alarm device, at ordinary times because of alarm valve closed, there is no pressure tube, once the valve open, there is pressure, pressure switch, alarm signal to the control center. Water flow indicator is the function of monitoring pipe flow condition, when the water flow out of date, leaf blade deflection, make the electric contact through to signal. The signal valve indicator used often and water.

We set up a pressure switch in the basement of the building, with 8300 module monitoring [4]. When the fire sprinkler water, the pressure switch action to return to the alarm signal, while the direct linkage control spray pump start. In the other layer including the ground floor each layer are set two water flow indicator and signal valve with a single I/O module 8300 monitoring, after the fire alarm signal to the control room only, as shown Fig. 2:

\section{Building Internal Wiring}

The building integrated fire control, automatic fire extinguishing control, laying lines, such as communication, emergency lighting and emergency broadcast should wear metal protection, and dark apply within the burning body structure, the thickness of protection layer should not be less than $30 \mathrm{~mm}$. When it is necessary for surface, fire prevention measures should be taken on a metal pipe. 
Transmission lines of automatic fire alarm system should be used in metal tube, the flame retardant processing hard plastic tube or enclosed slot wiring protection way.

When the flame retardant processing of cable is used, do not wear metal pipe protection, but should be laid in the cable shaft, or laid in the ceiling.

The line core selection of the transmission line of fire automatic alarm system, in addition to the technical requirements of automatic alarm device, must also meet the mechanical strength requirements. The minimum cross-sectional area of copper core insulation wire, copper core cable should not be less than the provisions of Table 1:

Table 1: Several passive wireless technologies in the field of green building

\begin{tabular}{|c|c|c|}
\hline Serial number & Category & $\begin{array}{l}\text { The minimum cross section } \\
\text { area of wire core }\left(\mathrm{mm}^{2}\right)\end{array}$ \\
\hline 1 & $\begin{array}{l}\text { In the insulation of the pipe } \\
\text { laying wires }\end{array}$ & 1.00 \\
\hline 2 & $\begin{array}{l}\text { Trunking laying insulated } \\
\text { wire }\end{array}$ & 0.75 \\
\hline 3 & Multi-core cable & 0.50 \\
\hline
\end{tabular}

\section{Fire Display Panel}

AHG2015 fire display panel is specifically designed for AHGBUS circular loop technology, takes up an address on the bus. When the fire breaks out, through the corresponding LED lights lit a fire on the display panel to display the location of the fire [5], the indicator light is programmable.

AHG2015 function characteristics:

Built-in microcomputer and data memory, without writing code and other electronic manual setting, saving installation time and labor;

Energy-saving micro power design, working current $80 \mathrm{~mA}$ or less;

Have perfect self diagnosis function, can to its operation state for testing;

Fire alarm system design as shown Fig. 3:

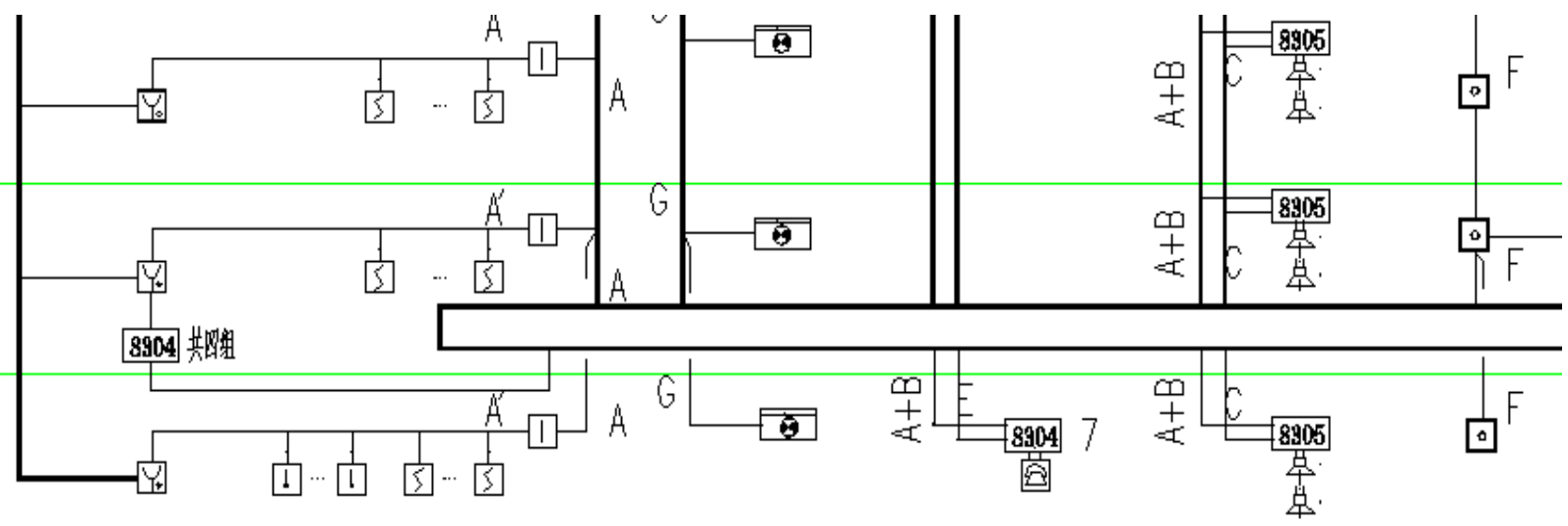

Fig.3. Fire alarm system

\section{Linkage Control System Design}

By manual or automatic way all the integrated fire control equipment, including underground fire hydrant pump, spray pump, and the top positive pressure blower, exhaust machine with double the I/O module in 8303 and 8302 a control switch module, in addition to the automatic control, the more lines in the center of the fire control system of manual control directly. In addition, the fire hydrant button can directly start the fire pump, pressure switch can directly start the spray pump, a layer of smoke exhaust valve, fire dampers and other layers fire 8301 control valve with a single I/O module, 
a fire started by the requirement of various kinds of fire fighting equipment, implement the elevator landing, and cut off the power supply, such as air conditioning, fire load normal lighting power supply.

The building fire linkage control system [6] is shown in Fig. 4: :

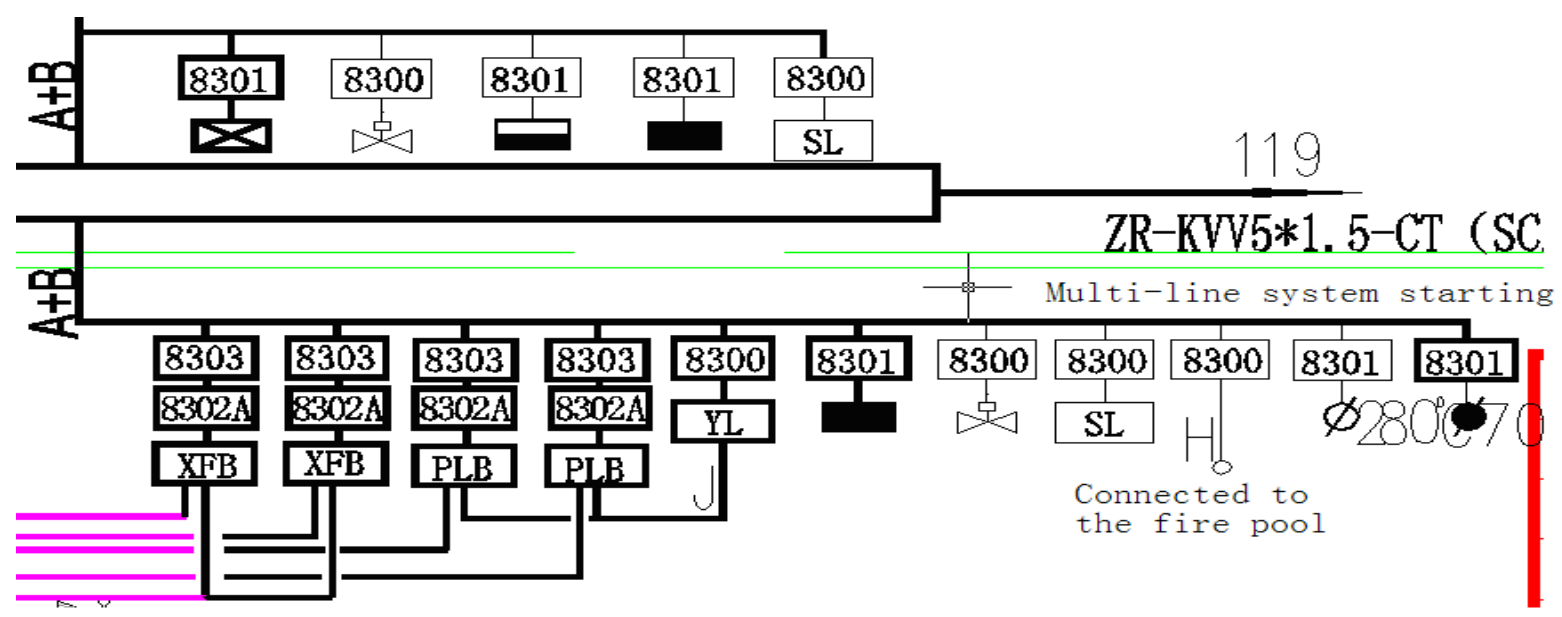

Fig.4. Linkage control system

\section{Lighting Load Layout}

According to the following principles:

Lighting single-phase current in each branch circuit should not exceed 16A, a single branch circuit the lamps (socket) number should meet the relevant requirements, the general can bring lamps 12 to 13, socket 7 to 8 only.

Each lighting switch should not be too much of the light source controlled by several, stadiums, theaters, lounges, waiting rooms and other public places should be centrally controlled.

Power supply radius should meet the requirements, generally no more than 30 meters.

Socket is not connected with the lamp in the same branch circuit.

In the buildings, shopping malls, underground large area lighting adopts centralized control, as shown in Fig. 5:

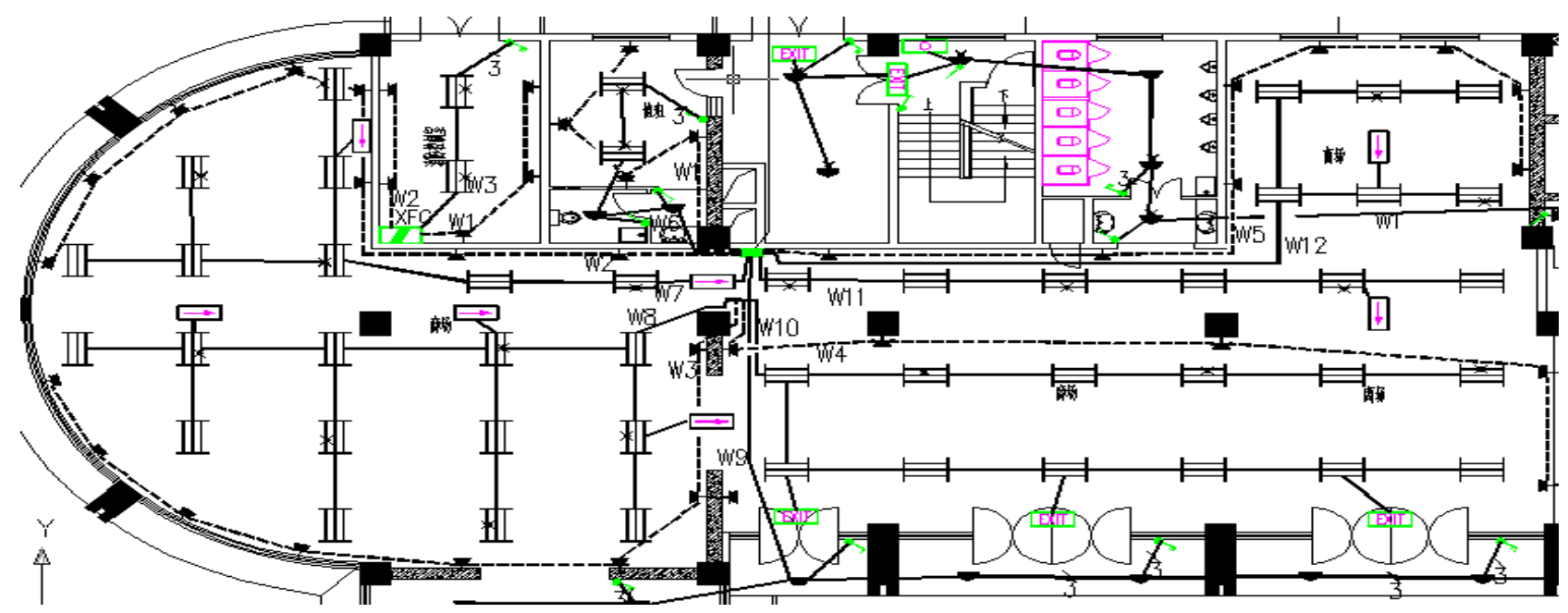

Fig.5. Lighting plan on the first floor mall 


\section{Summary}

The height of the high-rise building is characterized with the root cause of the fire characteristics of weak current system design. Reality, the fire fighting capability of mobile fire vehicles can not keep up with the pace of development of high-rise buildings. Therefore, the fire protection design of tall buildings should based on the inside of the building fire protection system construction, efforts to improve the fire detection, alarm, fire fighting automatic functions such as, fire will be nipped in the bud. On the external of the building, fire alarm system, intelligent system mainly refers to the meaning of the linkage. Fire control system is a composed of buildings, equipment, and electrical and other professional whole, close co-operation between professional and comprehensive arrangement is very important. These should be the basic ideas to ensure the safety of high-rise building.

\section{Acknowledgement}

This paper is aided by following Dongguan Institute of Technology "The key technology research of the mobile WiMAX system ", which project number: 2008108101006.

\section{References}

[1] Kodjovi Dodji Obilale. Introduce of urgent lighting [R] U. S. A: Analog Devices, Inc, 2005(9)

[2] G.-Y. Tang J. Li "Optimal fault diagnosis for systems with delayed measurements," [J].IET Control Theory Appl., 2008, Vol. 2, No. 11, pp. 990-998

[3] Lo.S.M, Fang. Z, zhi.GS. The development of SGEM: an evacuation model for fire safety design in buildings. The Hong Kong Surveyor. 2001

[4] RAM.K.G, ESSA.G.A. Impact of Emergency Shutdown Devices on Relief System Sizing and Design [J]. Journal of Loss Prevention in the Process Industries, 2009,22(1): 35-44

[5] Laszlo Kajtar, Miklos Kassai, Laszlo Banhidi. Computerised simulation of the energy consumption of air handling units[J]. Energy and Buildings, 2012, 45(2): 54-59

[6] http://www.eccn.com 